\title{
Extensive small-bowel diverticulosis identified with the newly introduced On Demand Enteroscopy
}

\section{system}
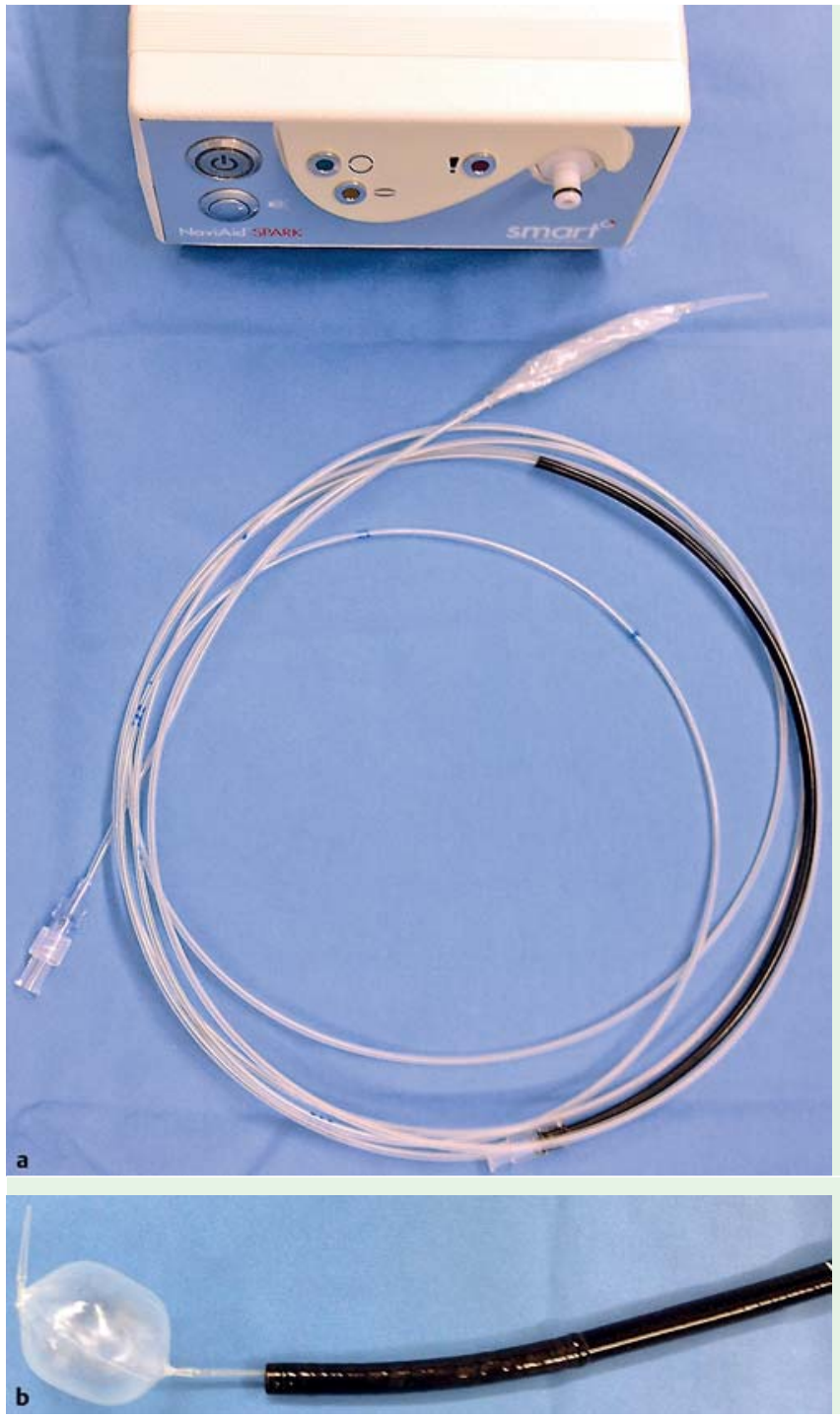

Fig. 1 a The disposable parts of the On Demand Enteroscopy (ODE) system for balloon-assisted enteroscopy. $\mathbf{b}$ The disposable, inflated ODE balloon at the tip of the scope.
The recently introduced On Demand Enteroscopy system (ODE; NaviAid AB, Smart Medical Systems, Ra'anana, Israel) enables deep small-bowel enteroscopy using standard endoscopic equipment. The ODE device consists of a disposable balloon that is advanced through the working channel of a standard endoscope equipped with a working channel of at least $3.8 \mathrm{~mm}$ ( Fig. 1). To the best of our knowledge, there are currently no published reports on the use of this new technique.

A 64-year-old man presented with abdominal pain, anemia and positive hemoccult. His physical examination was unremarkable and the laboratory parameters were within the normal reference ranges, except for a low hemoglobin level $(10.2 \mathrm{~g} / \mathrm{dL})$. Celiac disease and lactose intolerance had already been ruled out and previous esophagogastroduodenoscopy (EGD) and colonoscopy had not revealed any bleeding source. In view of the positive hemoccult but negative upper and lower endoscopic examinations, a decision was made to use ODE deep small-bowel enteroscopy. The endoscope was advanced into the distal duodenum, and the ODE system was inserted through the working channel of the endoscope (Pentax i10 L, Tokyo, Japan) and advanced ahead of the endoscope inside the small intestine. Next, the balloon

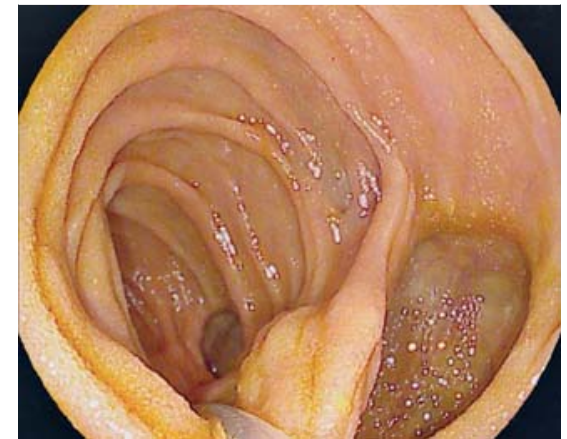

Fig.2 Massive diverticulum next to the inflated balloon, approximately $180 \mathrm{~cm}$ from the pyloric region, in a 64-year-old man with abdominal pain, anemia and positive hemoccult.

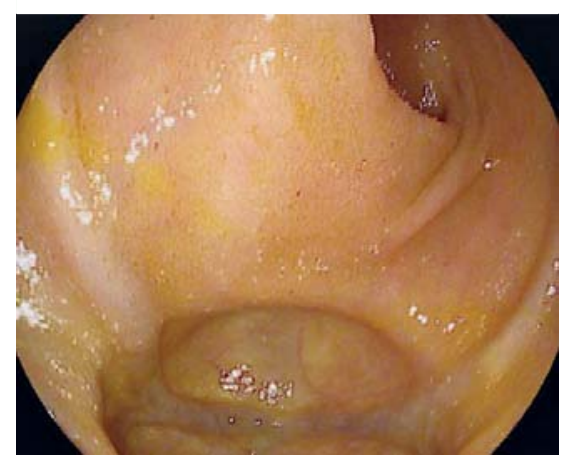

Fig. 3 Diverticular sacs with mucosal atrophy and distorted vascular pattern.

at the distal tip of the ODE device was inflated. Once the balloon was completely inflated, the endoscope was pushed forward while the anchored balloon was pulled gently backwards. The small-bowel was straightened with the inflated balloon placed at the distal tip of the endoscope while the endoscope was gently pulled backwards. This approach allowed us to introduce the endoscope within $12 \mathrm{~min}$ utes to a maximum length of $180 \mathrm{~cm}$ from the pyloric region. The next advancement step revealed a huge (20-mm diameter) diverticulum ( $\bullet$ Fig. 2 ) which had come to be situated next to the inflated balloon during the last pulling operation, however, there were no signs of mucosal damage. The endoscope was carefully advanced and several more large-sized diverticula were found at approximately $200 \mathrm{~cm}$ from the pyloric region ( $\mathrm{Fig.} 3$ and $\bullet$ Video 1 ). 
This case report is interesting for multiple reasons. First, we have given a detailed description of the procedure employing the newly introduced ODE system, which may assist with further use of this technique. Second, our report adds to the growing literature on advanced endoscopic imaging methods for the small bowel $[1,2]$. Lastly, we have demonstrated the safety of the ODE system while identifying an unusual case of small-bowel diverticulosis $[3,4]$.

\section{Video 1}

Extensive small-bowel diverticulosis clearly seen in the deep small bowel.

Endoscopy_UCTN_Code_TTT_1AP_2AD

Competing interests: None
Gian E. Tontini ${ }^{1,2}$, Martin Grauer ${ }^{1}$, Hakan Akin ${ }^{3}$, Michael Vieth ${ }^{4}$, Hüseyin Tasdelen', Maurizio Vecchi ${ }^{2,5}$, Markus F. Neurath ${ }^{1}$, Helmut Neumann ${ }^{1}$

${ }^{1}$ Department of Medicine I, University of Erlangen-Nuremberg, Erlangen, Germany

${ }^{2}$ Gastroenterology and Digestive Endoscopy Unit, IRCCS Policlinico San Donato, San Donato Milanese, Italy

${ }^{3}$ Department of Gastroenterology, Marmara University, Istanbul, Turkey

${ }^{4}$ Institute of Pathology, Klinikum Bayreuth, Bayreuth, Germany

${ }^{5}$ Department of Medical Science for Health, University of Milan, Italy

\section{References}

1 Fry LC, Vormbrock K, Olano C et al. Smallbowel endoscopy. Endoscopy 2011; 43: 978-984

2 Mönkemüller K, Neumann H, Fry LC. Enteroscopy: Advances in diagnostic imaging. Best Pract Res Clin Gastroenterol 2012; 26: 221-233
3 Ross CB, Richards WO, Sharp KW et al. Diverticular disease of the jejunum and its complications. Am Surg 1990; 56: 319-324

4 Longo WE, Vernava AM3rd. Clinical implications of jejunoileal diverticular disease. Dis Colon Rectum 1992; 35: 381-388

Bibliography

DOI http://dx.doi.org/

10.1055/s-0033-1344831

Endoscopy 2013; 45: E350-E351

(c) Georg Thieme Verlag KG

Stuttgart · New York

ISSN 0013-726X

Corresponding authors Helmut Neumann and Gian E. Tontini Department of Medicine I University of Erlangen-Nuremberg Ulmenweg 18

91054 Erlangen

Germany

Fax: +49-9131-8535209

helmut.neumann@uk-erlangen.de gianeugeniotontini@libero.it 